\title{
Critique on the Research Article "Being a Narrative Inquirer in a Multicultural Landscape" by the Researcher JoAnn Phillion (2002)
}

\author{
Hastings Chim Ho Yeung ${ }^{1, *}$ \\ ${ }^{1}$ University of Bristol, UK \\ *Correspondence: University of Bristol, UK. E-mail: hoyeungmr@gmail.com
}

Received: November 16, 2014 Accepted: November 25, 2014 Published: December 21, 2014 doi:10.5296/ije.v6i4.6632ＵRL: http://dx.doi.org/10.5296/ije.v6i4.6632

\begin{abstract}
This paper will focus on accessing the research article "Being a narrative inquirer in a multicultural landscape" by the researcher JoAnn Phillion (2002), by explicitly and critically discussing the synopsis of the study, its approaches to educational research with explanations, the main strengths of this research as a contribution to educational policy, practice and knowledge. It is to be followed by a critical evaluation on how theory, research design, methods and researcher values influenced the analysis and conclusions of the articles. Possible improvements will be suggested for the potential betterments during the refining process. A conclusion with a sharp overall assessment on the study will be included.
\end{abstract}

Keywords: narrative inquiry, multicultural landscape, research paradigm, positivism 


\section{Introduction}

This paper will focus on accessing the research article "Being a narrative inquirer in a multicultural landscape" by the researcher JoAnn Phillion (2002), by explicitly and critically discussing the synopsis of the study, its approaches to educational research with explanations, the main strengths of this research as a contribution to educational policy, practice and knowledge. It is to be followed by a critical evaluation on how theory, research design, methods and researcher values influenced the analysis and conclusions of the articles. Possible improvements will be suggested for the potential betterments during the refining process. A conclusion with a sharp overall assessment on the study will be included.

\section{Synopsis of the study}

In accordance with Phillion (2002), the major aims of this study are to elucidate the real picture of impartation and acquisition in a culturally diverse context through the lens of narrative inquiry by Phillion with the qualitative input reflected in notes, journals, reflective writing and stories written for a teacher participant to structure the multicultural life in school. During the inquiry process, Phillion herself investigates the process of transforming to be a narrative inquirer contextualised in multicultural diversity and deduces the new pedagogical perspective towards the minority students in classrooms. Ultimately, the implication of narrative multiculturalism is underpinned by comprehending multicultural impartation and its acquisition and later the elaboration of the successful strategies deployed on minority students.

The research is conducted in the teacher participant's grades 4/5 classroom in Bay Street School located in Toronto, Canada, where there is a mixture of various races and rather low socio-economic students. Phillion (2002) indicates a further understanding multicultural teaching and learning interaction between the participants and the researcher, including the social and personal dimension. She applies the four directions of a narrative inquiry raised up by Clandinin and Connelly (1994, 2000), which stretches from inward, the intrinsic feeling experienced by the teacher, to outward, the environment and its rigor to the subject, onto her study. Their relations are being reflected by the exposure of backward and forward review chronologically through the in-depth dissection of the journals and other reflective writing as field texts notes and stories. The three basic qualities, including "Thinking narratively, being in the midst of lives, making meaning of experience in relationship" (Phillion, 2002) are considered the inquiry methods whereas the "objectivity, distance and triangulation were methodological standbys." In the related subject, the primary audience this research targets would be the practitioners of multicultural education, the curriculum planners and teachers who serve minority in the multicultural context.

\section{Research Classification}

According to Bassey (1996), the paradigms or the approaches of educational research place 
the core values and orientation of the researches. Bassey outlines the four salient paradigms: positivism, interpretivism, critical theory and postmodernism.

The positivists assume that social science can be studied as an object, which resembles the way they commit in investigations of natural science. Nevertheless, positivism is under criticism of its capsulation of the researcher from the implementation of research without acknowledging that the researchers would inevitably implant values, judgements and even bias on the research. Inevitably, humanity is considered to be emotionless and entirely objective. Positivist researchers conduct experiments and tests in a controlled and measurable manner with which to provide evidence for a hypothesis. In contrast with positivists, the interpretivists advocated by Habermas and Foucault cited by Usher (1996) in the mid-twentieth century, hold a paradoxical scope by focusing on the differences of the nature and social sciences as well as outstanding the interpretability of humanity upon the context and content, which further indicates there is always cohesive bonding linking up values and knowledge, or truth, because various perspectives are being beheld by individuals and events in which the researchers have to acknowledge the diversity of interpretations from all participants and even theirs to construct the situation to the research. Interpretivist research adopts the use of interviews, footnotes, journals and stories, which are all pragmatic for studying diversified variables during the research. Critical theory aims at alleviating the social inequality by transfiguring the society in the areas of sex, race, minority and the low socio-economical class. Carrying resemblance of interpretivism that researches should be value-laden, critical theory researchers emphasizes the ideology of initiating change by scrutinising diversified interpretations and values. Commonly adopted critical theory research methods that focus on collaboration with participants consists of interviews, small group discussions and the action research which is the most signified method in the concurrence with critical theory research, in which the rigor on these methods should be embedded to refrain from discrimination. Postmodernism is another spectrum of critical theory research which, similarly, studies the correlations between individuals and social relations, but explicitly puts emphasis on individuals as constructs and to what extent these constructs are glued by examining the language, with which the interconnection between power and knowledge is reviewed by interpreting meaning underlying in the language and the hierarchy of those who use the language. Standard research methods consist of triangulation of audio and visual taping of dialogues, the authority of the participants and the social implications of the observers.

According to Guba and Lincoln (1994), Phillion's research has the inclination to be categorised as the interpretivism research. Among the 10 areas of the cross paradigm's positions, this article has demonstrated some of the identifiable features as described in the paradigm positions of the cross-paradigm analysis.

First, as indicated by Phillion, the study is to place intense concern on issues of multiculturalism and multicultural education. In this point of view, Phillion, as stated in the paradigm position, is actively engaged as both a participant and facilitator in the process. Additionally, interpretivism emphasizes the researchers' consistent amendments when there are derivations from original constructions. In this study, the researcher revises the research 
design intermittently from her initial expectation to the real interactions because of the shift of the acquaintanceship towards the subject Pam. In terms of accumulation of knowledge, Phillion has demonstrated her devotions by "throwing herself into the inquiry into her relationship with Pam", observation and participation in her class, with continuous conversations with her and the writing up of volumes of field notes. For the maintenance of the inquiry quality, the writer deploys certain tactics to capsulate herself from the relationship from Pam during the accommodation of the narrative multiculturalism by means of retaining filed notes, reflective writing, classroom stories and imaginative pieces which is to assure the trustworthiness of the study. Given that the role of values in interpretivists is of high relevance of its outcomes, Phillion places values in scrutinizing the effective strategies in teaching immigrants and minority students in the school which assists the lower social-economic class from minority. Unambiguously, Phillion presents to be the facilitator of the inquiry in which she exchanges her ideas with Pam, ranging from her personal beliefs, race, social-economy and eventually how these interactions and experiences are fused into the multicultural landscape and ultimately the acquisition of multiculturalism. Furthermore, interpretivists ethics are implicitly underpinned in the inquiry due to the fusion of the researchers' values into the studies. Phillion intensively discusses with Pam the moral dispositions, expectations, beliefs and values laden in pedagogy, which fulfils the interpretivists' standard on ethics. Nevertheless, as Guba and Lincoln (1994) mentioned, the researcher may be confused by the paradoxical situations caused by the unanticipated and instable interactions with the participant, whereas, as described by Phillion, the relationship building with Pam resembles "a roller coaster ride".

\section{Strengths of the research}

Kennedy (1997) indicates that the research and the practice should be connected with four areas, including the persuasiveness and authority of research, its relevance, the accessibility to teachers and the stability of the education system.

To the extent of the persuasiveness and authority, persuasive evidence is crucial for research design to eliminate variables and the interconnections with other variables. Phillion, at this stance, has embodied a comprehensive and persuasive research design to investigate the envision of narrative multiculturalism by initially introducing its background and context to how Pam's classroom can be related to stories of multicultural teaching and learning and, finally, in this paper the immersion of herself into the teaching of Pam and the interactions with her, in which she collects field notes, texts and journals as the raw materials, with Clandinin and Connelly $(1994,2000)$ notion of inward, outward, backward and forward directions of narrative inquiry as the analytic framework, as well as three fundamental qualities : thinking narratively, being in the midst of lives and making meaning of experience in relationship to establish as roots for the methodology. In order to diminish the ambiguity caused by the relationship with Pam, Phillion adopts objectivity, distance and triangulation to refrain the suspicion. All in all, the research design and the evidence achieved are technically persuasive, owing to the advanced defining of methodology, unambiguous interpretation of 
the raw materials.

Regarding the relevance of research, Kennedy (1997) argues that research should be carried out in the classroom instead of the laboratory since the insights reflected from the classroom dissects the teacher's real encounters and their dilemmas with the uncertainty unpredicted by the researchers in the ivory towers. As aforementioned, Phillion's immersive actions and participation into Pam's daily teaching experiences at root manifests Kennedy's notion of incorporating the research and even the researcher itself into the classroom with which the details of teaching and learning in a multicultural classroom are clearly illustrated, that therefore her study is of relevance to educational practitioners serving the minority. Kennedy also states that there is always lack of connection between research and teachers' accessibility to research findings no matter how literally and conceptually, which simply value the importance of prioritising the teachers' beliefs and values upon the research design. Phillion in her paper has repeatedly reinforced her recognition of Pam's values, beliefs and pedagogical rationale, particularly after certain development established with Pam. Herein Phillion is especially interested in Pam's beliefs on teaching and the appropriate role Pam should play in the disadvantaged ethics' classrooms. With this prerequisite, her work is considered to be highly accessible to those who teach in similar context.

Drawing on the notion of the potential of narrative and experimental approaches in multicultural inquiries (Phillion, He, \& Connelly, 2005), from the prism of the development of multiculturalism Phillion's work can also be reflected as the milestone along the path on cultivation on multicultural education specifically on the perspectives of the researchers who incorporate themselves into the lives of the participants, leading to the possibilities to their betterment, as herein as stated by Phillion, the successful strategies in working with immigrants and minority students, rather than just elucidating the existing theories and frameworks for Phillion in her work, points out that both theories and structures could be ambiguous nor contextualised to the actual interactions between the reciprocal actions of Pam and Phillion. In short, Phillion has to comprehend Pam as a person with the vivid characters which are unlikely to be construed by theories. This highly outstands the crux of understanding the participants in terms of the acquaintanceship instead of dissecting them through the microscope of the theories. Additionally, the inquirer has to recognise how the experiences they interpret can be linked to the socio, cultural and historical contexts. Phillion, in this regard, deliberately selects a school for her study with minority students disadvantaged by low socio-economic conditions, which she thinks it can be epitomised among other resembled school settings. These two features represent how the narrative inquirers can transfigure the social inequalities and ultimately the whole community.

In a wider scope on shifting paradigm, Phillion's work can be considered as a countenance towards the "seventh moment" (Phillion, He, \& Connelly, 2005), which refers to the deployment of narrative in perceiving the sophistication of human behaviour, and the continuality embedded in the sixth moment, which is the time to reconsider how participants' experiences can be shaped and consolidated by participants themselves instead of being merely interpreted. As stated in the abstract Phillion realises that the dormant existing western scientific perspective has restricted the perception towards multicultural studies and 
therefore led a critique to the existing literature. As a result, Phillion's work not only arouses the rising interests upon multiculturalism, but also inspires the shift of adopting narrative inquiry into multiculturalism which further seeks the potential values of narrative inquiry.

Concerning the significance to readers and other relevant scholars and researcher, Phillion inspires them to transform themselves to be adaptive to changes, fluid and reciprocal when ones are trying to employ narrative inquiry into multiculturalism in which authentic narratives should primarily be converged to language and culture in real-living contexts and ultimately contributes to the development of multicultural theories. In a practical perspective, multicultural teachers can consider this study the mirror reflecting their own pedagogical rational and strategies, while the specialists in bureau can exemplify the study as a reference when piloting multicultural teaching in different schools.

\section{Critical Evaluation}

Boaz A and Ashby D (2003) lists out several qualities to critically evaluate educational researches. The first concern will be if the research methods are appropriate to the question being asked. According to interpretivism, the nature of knowledge is constructed through various interpretations of situations, which can be differentiated by factors on gender, ethnic, economic, cultural, political and social context. As aforementioned, this research aims at finding out the benefit of narrative multiculturalism to understanding multicultural life and multicultural teaching and learning. Such interpretations require consistent amendments when there are differences from constructions simultaneously. In this study, Phillion revises the directions of the research from what to expect to what to experience because of the shift of the acquaintanceship towards the subject Pam.

The context of the research is deeply concerned with the research objectives and its methodologies (Angen, 2000). Phillion, in her work, explicitly clarifies the historical context by presetting the purpose to the entity a critique to the existing literature upon the new methodologies investigating multiculturalism, which shows the development stage of narrative inquiry. The social context of the research is similarly embedded in the abstract and the introductory paragraphs, portraying the downtown community school located in Toronto, Canada, where could be the epitomised setting reflecting the minority and races in a multicultural context.

According to Guba and Lincoln (1994), interpretivists constitute their knowledge with a structural, organised and complicating construction in the extent of interpretivism process and most importantly the immersed vicarious experience illustrated with supplementary narratives, reports, journals and stories. Phillion in this area has demonstrated her enthusiasm in "throwing herself into the inquiry into her relationship with Pam", sharing her joys, sorrows and difficulties, having on-going conversations with her and wrote volumes of field notes. In this process, she believes that life and research are inseparable. They are one and the same.

It is, moreover, significantly crucial to critically review if there is a clear connection to an 
existing body of knowledge. Phillion (1999) in the first paper of the series highlighted the general ideas of narrative multiculturalism and later the second one (Phillion, 2000) relating stories of multicultural teaching and learning. In the final paper, there are varieties of concepts based on the existing knowledge concerning the narrative inquiry utilised. For instance, the four directions of a narrative inquiry from Clandinin and Connelly (1994, 2000), the three fundamental qualities to become a narrative inquirer : thinking narratively from Clandinin and Connelly (2000), being in the midst of lives from herself (1999) and making meaning of experience in relationship from He and Phillion (2001). In the 'look forward' session, Phillion has positioned her work as the 'developing discourse' on multiculturalism and broadly contrasted her work to the existing literature, including the one concerned with philosophical base on ethics and historical and social context of multiculturalism from Greene (1993), and that on ethnographers immersing themselves in the lives of their participants (Soto 1997), as well as the autobiographic writing by teachers as Paley(1979), Solniciki(1992) and Thiessen (1996) of their first hand experiences onto the multicultural classrooms, and even more vicariously the immigrants themselves exploring their personal encounters in societies and schools (Kingston 1975, Hoffman 1989).

Phillion additionally states two resembled narrative inquiry from Carger (1996) concerning with a Mexican-American family and He (1998) which detailed the paradox of three Chinese female teachers resided from the cultures. Nevertheless, no counter literature is shown to scrutinise her own work or the notion of narrative inquiry in multiculturalism. When critically reviewing the rigor of considering whether supporting and countering literature have been elucidated, as aforementioned, the evidence in countenance or contradicts the researcher's interpretation are unobviously demonstrated, leading to certain ambiguity of researcher's intention on enhancement of internal and external validity. Moreover, the restrictions are not mentioned in this study.

Additional concern is, in accordance with Boaz A and Ashby D (2003), placed on to what extent if the criteria for sample selection, data collection and analysis are clear and systematically applied, as well as whether findings are systematically reported. Standardised with the features of the interpretivism, Phillion collects abundant of field notes, records in the classroom observation and the immersion into Pam's life for 20 months, and the journals, reading for standbys with which an abundance of original evidence elucidating Pam's pedagogy and Phillion's inquiry process suffices the furnish of the conclusions. Notwithstanding that the findings are systematically reported which are based on the analysis undergone with the four directions as well as three narrative qualities underpinned in the delivery. Herein Phillion has demonstrated a clear categorization of data, including the field notes, journals and stories and as raw materials for the research. The analysis, additionally, is rigorously relied on the mentioned four directions of a narrative inquirer from Clandinin and Connelly as the analysis of field notes and records on Pam and the three fundamental qualities to assess Phillion's inquiry process. Conclusively, evidence reported suffices the justification of the conclusions. Considering resembled impediments of other disadvantaged school encounter, the selection of the school is symbolic and would be applicable to resembled contexts. The criterion of selecting the participant Pam is, nonetheless, remains 
unstated in this paper, which might reduce the validity of the research. In the light to the responsiveness on the circumstances and issues of real-life social settings during the study, the adaptation of the research design is directed to how Phillion transforms her mindset by categorisation and objectification of Pam to the inherent recognition and acknowledgement of Pam as a person. The shift not only transforms Phillion's interpretation of Pam's teaching, but also her paradigm shift from solely an interpreter to a narrative inquirer who tries to observe and study how Pam correlates the minority students and the authority amidst. Such observations based on interpretation of meaning underlying in the discourses elucidate the social implications of the observers, causing the shift of the overall research design from interpretivism to postmodernism (Bassey, 1996). One of the evidence is Phillion reinforces the ideology of transform researchers to be adaptive to changes, fluid and reciprocal in her conclusion.

Featuring with an interpretivist epistemology, the relationship between the researchers and researched is convergently considered in which the researched is assumed to have been informed categorically (Boaz A and Ashby D, 2003). Phillion in her work lays primary focus on the description of her tension, stress, reconcile and integration of both Pam and Phillion ideas and ideology towards education. As a narrative inquiry research based on hermeneutics, Phillion demonstrates clear and thorough understanding into the relationship between the researchers and the subjects. Conversely, it remains unknown whether the subject, Pam, has been fully informed in accordance with the absence of such evidence.

When concerning the above relationship between the researchers and the researched, the role of values in interpretivists is of high relevance of its outcomes whereas the unrelated values should not be incorporated into the study (Guba \& Lincoln, 1994). More crucially, the values must be more concerned with the interests of poverty or minority in which the inquirer is considered the major facilitator during the inquiry. In Phillion's study's setting, the school serves the disadvantaged social class from refugee and immigrants with English as the second language and thus the effective strategies in teaching immigrants and minority students should be top-prioritised. Categorically, Phillion sees herself as the facilitator of the inquiry, as a facilitator of the inquiry she brings her personal experience with the vicarious interactions with Pam in even a wider dimension of race, social-economy and ultimately the convergence into the multicultural landscape and the acquisition of multiculturalism

Boaz A and Ashby D also raises the concern on how interpretivists should be grounded at the avoidance of the deception, by imposing sufficient consideration on how findings are derived from the data and how the validity of the findings were tested. As mentioned, Phillion applies the three fundamental qualities to analyse her own narrative inquiry and the four directions of a narrative inquirer to assess and interpret the field notes and journals. Phillion collects. Nevertheless, how the validity of the findings are validated by the academic scrutiny and interpretations of Pam's records, filed notes, journals and stories are absent. Besides, how Pam perceived Phillion's materials accommodated in an interview context is insignificantly presented, which inevitably leads to the on-sideness of Phillion's work (Eisner, 1992). In order to ensure the quality of the inquiry, interpretivists have proposed sets of criteria which are in correspondence with the ones similar with positivist, such as the trustworthiness, 
transferability, dependability and confirmability as well as the authenticity criteria. In this study, the writer demonstrates various precautions to withdraw herself from the relationship from Pam to augment the trustworthiness when conceptualizing the narrative multiculturalism by retaining field notes, reflective writing, classroom stories and imaginative pieces, which is meant to enhance the trustworthiness of the study.

Correlated with the underlying values laden by the inquirer, ethics are implicitly embedded in the inquiry due to the penetration of the researchers' values into the studies. Phillion indicates that she discusses the moral dispositions, expectations, beliefs and values laden in pedagogy, herein the participant, Pam, also states hers during the discourses with Phillion. The ethics, in this regard, are vitalized in this study. However, as Guba (1994) mentioned, the researcher may be paralyzed by the ambivalence caused by the uncertain and unstable interactions with the participant. For instance, as described by Phillion, the relationship building with Pam is similar to "a roller coaster ride"

Notably the underlying value is grounded at the stance of the researchers who are clear about their own juxtapositions in relation to the research topic as a matter of fact that the inquiry aims at understanding and the reintegration of the existing values and beliefs people and the inquirer have. As mentioned by Phillion, the study is to investigate the intense concern for issues of multiculturalism and multicultural education. In this point of view, Phillion, as stated in the paradigm position, is playing as a participant and facilitator in the process. It's quite apparent that Phillion is clear about the stance she is standing. As an narrative inquirer based on the hermeneutics, the researcher has to be the facilitator, the speaker and the orchestrator of the inquiry process, who strives for the very best of the participant, rather than merely the interpreter of the inquiry. Therefore, she fully immersed herself into Pam's life.

\section{Possible improvements}

Undoubtedly objectivity is also an essential in positivist research as similarly as constructivist one does (Elsner, 1992) in which it can be achieved by opening it up to academic and professional scrutiny with means of rigorous dissections by critics and debates of other community members.

In view of the absence of other researchers' interpretation upon Phillion's elucidations of her inquiry of the multicultural classroom, rigorous scrutiny in great depth based on elimination of Phillion's personal perception is required in which the scholars focusing on the narrative inquiry based on the multiculturalism should be requested to scrutinise her field notes, stories, records and even the copious articles, journals and reflective writing she relies on to maintain objectivity. This highly increases the credibility and validity (Elsner, 1992). In addition to the critical scrutiny from the community, contradictory literature dissenting the narrative inquiry on multiculturalism should be fully demonstrated to indicate Phillion's verification and selection criterion as well as her rigor to refrain her work from one-sidedness.

Similar as the validity of quantitative researches, the trustworthiness is deeply concerned the objectivity of the qualitative ones with which it can be established by member check, 
interviewer corroboration, peer debriefing, prolonged engagement, negative case analysis, auditability, bracketing and balance (Angen, 2000). In order to enhance the trustworthiness, member check, namely informant feedback, can be done in an interview at the conclusion stage by revealing interpretation and reports to Pam and later asking the her questions for confirmation of the findings and if the summaries can reflect their perspectives and the implications behind their behaviours so as to minimize misinterpretations of the researchers. If the Pam is congruent with the accuracy and reflections, then the investigation is considered credible at this stance. If the member check implementation focuses on the people who are of no original participants, then the study can be said to have certain transferability, which in quantitative researches regarded as predictability, enabling the findings to be applicable to others under resembled contexts.

Angen (2000) highlights certain strengths in deploying member check into Phillion's study. First, Pam can construe what is behind their behaviour and amend their errors when the findings are wrongly interpreted beforehand or conversely add supplements whenever inadequate nor incomplete. It also demonstrates high validity, whereas ultimately avoids falsification of the information from being produced.

Inevitably, member check does encounter drawbacks (Angen, 2000), particularly in the way that findings are rather difficult to be clarified by Phillion nor comprehended by Pam. The member check implementation is also time-worn and costly in which Pam may be unwilling to attend the process due to the expiration of the research or the grievance aroused by the topic. On the other hand, Pam may just present what flavours Phillion or forgets what she has said beforehand if the researches are done for a long time or even distort her original interpretations when regrets her prior interpretations. Furthermore, member check can derive more original information to slow down the interpretation, which causes hindrance to accomplish the research. The repeatedly stated subjectivity of Phillion work, in certain degree, augments the difficulties in establishment of its reliability.

\section{Conclusion}

Narrative inquiry is to be signified as a kind of prominent approach studying multiculturalism in view of its highly interpretive characteristic and reflexibility. Notwithstanding that narrative inquiry is considerably an effective method of managing knowledge, particularly interpreting purely qualitative data as experience, history and personnel recount, nonetheless, Phillion states out not many investigations deploying narrative inquiry into multiculturalism is embodied as majority of work in the past is primarily related to philosophy derived in ethnic, culture, the construction of knowledge, language, history as well as the sociology, whereas there are frontier researchers similar to Phillion who step forward into the multicultural classroom and connect their own with personal experiences with the rigor happened inside the classroom. In short, the inquirers should fully immerse themselves into the participants so as to elucidate the fruitful perspectives from the multicultural classroom. At this stance, this study provides a road sign, a milestone towards the real-encounter practice regarding the narrative inquiry dedicated to multiculturalism. 
As aforementioned, there is a paradigm shift from hermeneutics to postmodernism when Phillion finds that she is internalising a shift of her methodology since she realises that her participant, Pam, can neither be categorised nor objectified for her hermeneutics interpretations but instead of the recognition and personification of her participant as a real person, who has the unique characters and with whom Phillion can discuss and share thoughts. By studying the field notes, journals and stories, which demonstrates the discourse analysis between Pam and Phillion, Pam's students, her principal and colleagues, the power distance, authorisation, and hierarchy among them. The way to study such discourse analysis is one of the features of postmodernism.

It is believed that the research can be further refined with academic scrutiny by other researchers and the member check with the participants, which is meant to filter certain personal biases and values during the inquiry through the disputation and disagreements to the extent that the researcher might be under threats of having misjudgements upon the patterns, behaviours and irregularities of the participants. Therefore, the critical tradition is the prevalence of avoiding the research from the impurities of perceptions nor falsifications from the researcher.

\section{References}

Angen, M. J. (2000). Evaluating interpretive inquiry: Reviewing the validity debate and opening the dialogue. Qualitative health research, 10(3), 378-395. http://dx.doi.org/10.1177/104973230001000308

Bassey, M. (1996). Three paradigms of educational research. Readings for reflective teaching in the primary school, 43-45.

Boaz, A., \& Ashby, D. (2003). 'Fit for purpose? Assessing research quality for evidence based on policy and practice', ESRC UK Centre for Evidence Based Policy and Practice, Queen Mary, University of London.

Carr, W. (1985). Philosophy, values and educational science. Journal of Curriculum Studies, 17(2), 119-132. http://dx.doi.org/10.1080/0022027850170202

Clandinin, D. J., \& Connelly, F. M. (1994). Personal experience methods. In Handbook of Qualitative Research. In N.K. Dezen and Y.S. Lincoln (ED.), Thousand Oaks, CA: Sage Publications(pp413-427).

Clandinin, D. J., \& Connelly, F. M. (2000). Experience and story in qualitative research: San Francisco: Jossey-Bass.

Crossley, M. (1996). Qualitative educational research in developing countries: current perspectives (Vol. 35): Routledge.

Crossley, M. (1999). Reconceptualising comparative and international education. Compare, 29(3), 249-267. http://dx.doi.org/10.1080/0305792990290305 
Eisner, E. (1992). Objectivity in educational research. Curriculum Inquiry, 9-15. http://dx.doi.org/10.2307/1180090

Guba, E. G., \& Lincoln, Y. S. (1994). Competing paradigms in qualitative research. Handbook of qualitative research, 2, 163-194.

Kennedy, M. (1997). 'The connection between research and practice' Educational Researcher, 26(7), 4-12. http://dx.doi.org/10.3102/0013189X026007004

Phillion, J. (1999). Narrative inquiry in a multicultural landscape: multicultural teaching and learning. Doctoral dissertation, University of Toronto

Phillion, J. (2002). Becoming a narrative inquirer in a multicultural landscape. Journal of Curriculum Studies, 34(5), 535-556. http://dx.doi.org/10.1080/00220270110108204

Phillion, J. (2002a). Classroom stories of multicultural teaching and learning. Journal of Curriculum Studies, 34(3), 281-300. http://dx.doi.org/10.1080/00220270110101788

Phillion, J. (2002b). Narrative multiculturalism. Journal of Curriculum Studies, 34(3), 265-279. http://dx.doi.org/10.1080/00220270110101797

Phillion, J., He, M. F., \& Connelly, F. M. (2005). The potential of narrative and experiential approaches in multicultural inquiries. Narrative \& experience in multicultural education, $1-14$.

Phillion, J. A., Connelly, F. M., \& He, M. F. (2005). Narrative and experience in multicultural education: Sage Publications, Incorporated.

Usher, R. (1996). A critique of the neglected epistemological assumptions of educational research. Understanding educational research, 9-32.

\section{Copyright Disclaimer}

Copyright for this article is retained by the author(s), with first publication rights granted to the journal.

This is an open-access article distributed under the terms and conditions of the Creative Commons Attribution license (http://creativecommons.org/licenses/by/3.0/). 